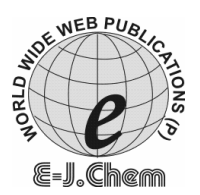

IIIIIIIIIII)

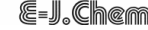

CODEN ECJHAO

E-Journal of Chemistry

http://www.e-journals.net

Vol. 3, No.1, pp 13-24, January 2006

\title{
Oxidation of Paracetamol Drug by a New Oxidant Diperiodatoargentate (III) in Aqueous Alkaline Medium
}

\author{
D. C. HIREMATH, C. V. HIREMATH AND S. T. NANDIBEWOOR* \\ P. G. Department of Studies in Chemistry, \\ Karnatak University, \\ Dharwad-580003, India.
}

Received 19 September 2005; Accepted 23 January 2006

\begin{abstract}
The kinetics of oxidation of anti-pyretic drug, paracetamol by diperiodatoargentate (III) (DPA) in alkaline medium at a constant ionic strength of $0.01 \mathrm{~mol} \mathrm{dm}^{-3}$ was studied spectrophotometrically. The reaction between DPA and paracetamol in alkaline medium exhibits 1:2 stoichiometry (paracetamol: DPA). The reaction is of first order in [DPA] and has less than unit order in both [PAM] and [alkali]. A decrease in the dielectric constant of the medium increases the rate of the reaction. The effect of added products and ionic strength of the reaction medium have been investigated. The oxidation reaction in alkaline medium has been shown to proceed via a DPA- paracetamol complex, which decomposes slowly in a rate determining step followed by other fast step to give the products. The main products were identified by spot test, IR, NMR and GC-MS. The reaction constants involved in the different steps of the mechanism are calculated. The activation parameters with respect to slow step of the mechanism are computed and discussed and thermodynamic quantities are also determined.
\end{abstract}

Key words:. Kinetics; mechanism; paracetamol drug; oxidation; Diperiodatoargentate (III).

\section{Introduction}

Paracetamol (PAM) (4-hydroxyacetanilide or acetaminophen or Tylenol or 4acetamidephenol) is a well-known drug that finds extensive applications in pharmaceutical industries. It is also used as an intermediate for pharmaceuticals (as a precursor in penicillin) and azo dyes, stabilizer for hydrogen peroxide, photographic chemicals. It is used as an alternative to aspirin. It is one of the most widely used of all drugs, with a wealth of 
experience clearly establishing it has the standard antipyretic and analgesic for moderate pain states. The action of paracetamol at a molecular level is unclear, but could be related to 14 S. T. NANDIBEWOOR et al.

the production of reactive metabolites by the peroxidase function of COX-2, which could deplete glutathione, a cofactor of enzymes such as PGE synthase $^{1}$. Which has high therapeutic value. There is hardly any work regard to the kinetics of oxidation of this drug in the literature (except in two cases ${ }^{2,3}$ ). In view of this, we have undertaken the study of the oxidation of paracetamol by diperiodatoargentate (III) in alkaline medium to understand the plausible mechanism and active species in such medium

Diperiodatoargentate (III) (DPA) is a powerful oxidizing agent in alkaline medium with the reduction potential ${ }^{4} 1.74 \mathrm{~V}$. It is widely used as a volumetric reagent for the determination of various organic and inorganic species. ${ }^{5}$ Jaya Prakash Rao, etal. ${ }^{6}$ have used DPA as an oxidizing agent for the kinetics of oxidation of various organic substrates. They normally found that order with respect to both oxidant and substrate was unity and $\left[\mathrm{OH}^{-}\right]$ was found to enhance the rate of reaction. It was also observed that they did not arrive the possible active species of DPA in alkali and on the other hand they proposed mechanisms by generalizing the DPA as $[\mathrm{Ag}(\mathrm{HL}) \mathrm{L}]^{(\mathrm{x}+1)-}$. However, Anil $\mathrm{Kumar}^{7}$ etal. put an effort to give an evidence for the reactive form of DPA in the large scale of alkaline $\mathrm{pH}$.

In the present investigation, we have obtained the evidence for the reactive species for DPA in alkaline medium. The DPA is a metal complex with Ag in 3+ oxidation state like $\mathrm{Cu}^{3+}$ in DPC and $\mathrm{Fe}^{3+}$ in hemoglobin. However, former is a single equivalent oxidant, having a structural similarity with DPA and DPC; and latter has structural dissimilarity with DPN. ${ }^{8}$ Hence, it is important and interesting for the detailed investigation of oxidation of PAM by DPA in aqueous alkaline medium.

\section{Experimental}

\section{Materials and Reagents}

All chemicals used were of reagent grade and double distilled water was used throughout the work. A solution of paracetamol (S.D. Fine Chem.) was prepared by dissolving an appropriate amount of recrystallised sample in double distilled water. The purity of paracetamol sample was checked by comparing its I.R. spectrum with literature data and with its m.p. $170{ }^{\circ} \mathrm{C}$. The required concentration of PAM was used from its aqueous stock solution. $\mathrm{KNO}_{3}$ and $\mathrm{KOH}$ were used to maintain ionic strength and alkalinity of the reaction respectively. Aqueous solution of $\mathrm{AgNO}_{3}$ was used to study the product effect, $\mathrm{Ag}$ (I).

Preparation of DPA: DPA was prepared by oxidizing $\mathrm{Ag}$ (I) in presence of $\mathrm{KIO}_{4}$ as described elsewhere ${ }^{9}:$ the mixture of $28 \mathrm{~g}$ of $\mathrm{KOH}$ and $23 \mathrm{~g}$ of $\mathrm{KIO}_{3}$ in $100 \mathrm{~cm}^{3}$ of water along with $8.5 \mathrm{~g} \mathrm{AgNO}_{3}$ was heated just to boiling and $20 \mathrm{~g}$ of $\mathrm{K}_{2} \mathrm{~S}_{2} \mathrm{O}_{8}$ was added in several lots with stirring then allowed to cool. It was filtrated through a medium porosity fritted glass filter and $40 \mathrm{~g}$ of $\mathrm{NaOH}$ was added slowly to the filtrate, whereupon a voluminous orange precipitate agglomerates. The precipitate is filtered as above and washed three to four times with cold water. The pure crystals were dissolved in $50 \mathrm{~cm}^{3}$ water and warmed to 80 ${ }^{0} \mathrm{C}$ with constant stirring thereby some solid was dissolved to give a red solution. The resulting solution was filtered when it was hot and on cooling at room temperature, the orange crystals separated out and were recrystallised from water.

The complex was characterized from its U.V. spectrum, exhibited three peaks at 216, 225 and $362 \mathrm{~nm}$. These spectral features were identical to those reported earlier for DPA. ${ }^{9}$ The magnetic moment study revealed that the complex is diamagnetic. The compound prepared was analyzed ${ }^{10}$ for silver and periodate by acidifying a solution of the 
material with $\mathrm{HCl}$, recovering and weighing the $\mathrm{AgCl}$ for $\mathrm{Ag}$ and titrating the iodine liberated when excess KI was added to the filtrate for $\mathrm{IO}_{4}^{-}$. The aqueous solution of DPA

was used for the required [DPA] in the reaction mixture. During the kinetics a constant concentration viz. $2 \times 10^{-4} \mathrm{~mol} \mathrm{dm}^{-3}$ of $\mathrm{KIO}_{4}$ was used throughout the study unless otherwise stated. Thus, the possibility of oxidation of PAM by periodate was tested and found that there was no significant interference due to $\mathrm{KIO}_{4}$ under experimental condition. Precaution was also taken to avoid the dissolution of $\mathrm{O}_{2}$ and $\mathrm{CO}_{2}$ in the solution by maintaining inert atmosphere with $\mathrm{N}_{2}$ throughout the study.

\section{Kinetic Measurements}

The kinetic measurements were performed on a Varian CARY 50 Bio UV-Visible Spectrophotometer. The kinetics was followed under pseudo-first order condition where $[\mathrm{PAM}]>[\mathrm{DPA}]$ at least 10 times at $25 \pm 0.1^{\circ} \mathrm{C}$, unless specified. The reaction was initiated by mixing the DPA to PAM solution, which also contained required concentration of $\mathrm{KNO}_{3}$, $\mathrm{KOH}$ and $\mathrm{KIO}_{4}$; and the progress of reaction was followed spectrophotometrically at $360 \mathrm{~nm}$ by monitoring the decrease in absorbance due to DPA with the molar absorbancy index, ' $\varepsilon$ ' to be $13900 \pm 100 \mathrm{dm}^{3} \mathrm{~mol}^{-1} \mathrm{~cm}^{-1}$. It was verified that there is a negligible interference from other species present in the reaction mixture at this wavelength.

The pseudo first order rate constants, ' $k_{o b s}$ ', were determined from the log (absorbance) $v s$ time plots. The plots were linear up to $85 \%$ completion of reaction under the range of $\left[\mathrm{OH}^{-}\right]$used. The orders for various species were determined from the slopes of plots of log $k_{o b s} v s$ respective concentration of species except for [DPA] in which non-variation of ' $k_{o b s}$ ' was observed as expected to the reaction condition.

\section{Results and Discussion}

Stoichiometry and Product Analysis

Different sets of reaction mixtures containing varying ratios of DPA to paracetamol in presence of constant amount of $\mathrm{OH}^{-}$and $\mathrm{KNO}_{3}$ were kept for $6 \mathrm{hrs}$ in closed vessel under nitrogen atmosphere. The remaining concentration of DPA was estimated by spectrophotometrically at $360 \mathrm{~nm}$. The results indicates that 1:2 Stoichiometry as given in equation (1).

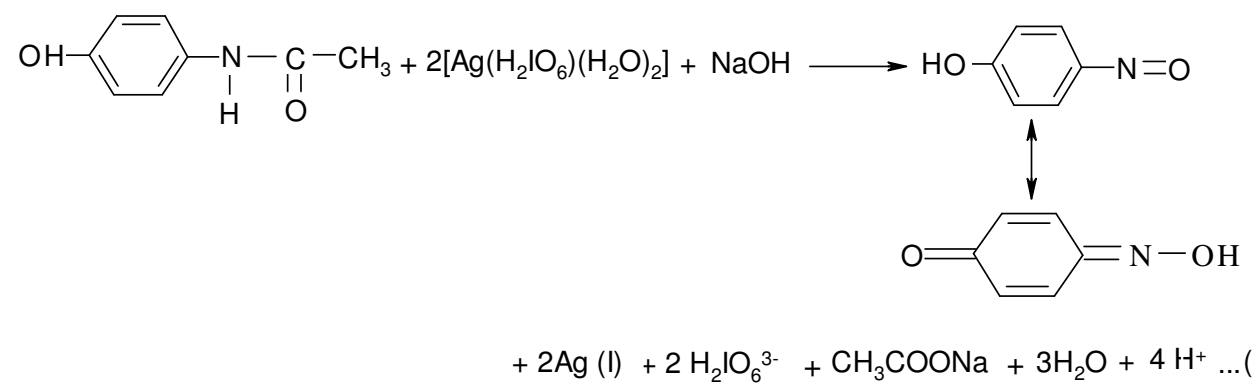

The main reaction product was identified as quinone oxime. The nature of quinone oxime was confirmed by its IR spectrum $\left(1652 \mathrm{~cm}^{-1}\right.$ due to $\mathrm{C}=\mathrm{O}$ stretching, $1615 \mathrm{~cm}^{-1}$ due to $\mathrm{C}=\mathrm{N}$ stretching of oxime, $3332 \mathrm{~cm}^{-1}$ due to O-H stretching), and its N.M.R spectra (singlet at $6.8 \mathrm{ppm}$ due to aromatic $2 \mathrm{H}$, singlet at $7.4 \mathrm{ppm}$ due to $2 \mathrm{H}$, singlet at $\mathrm{H}$ of $\mathrm{O}-\mathrm{H}$ ). It was further confirmed by its melting point $131{ }^{\circ} \mathrm{C}$ (literature m.p. $132^{\circ} \mathrm{C}$ ). Further, Quinone oxime was subjected to GC-mass spectral analysis. GC-MS data was obtained on a 17A Shimadzu 
gas chromatograph with a QP-5050A Shimadzu mass spectrometer using the EI ionization technique. The mass spectrum showed a molecular ion peak at $123 \mathrm{amu}$ confirming Quinone 16

S. T. NANDIBEWOOR et al.

oxime product (Figure 1). All other peaks observed in GC-MS can be interpreted in accordance with the observed structure of the quinone oxime. Sodium acetate was identified by spot test ${ }^{11}$. The formation of free $\mathrm{Ag}^{+}$in solution was detected by adding $\mathrm{KCl}$ solution to the reaction mixture which produced white turbidity due to the formation of $\mathrm{AgCl}$.

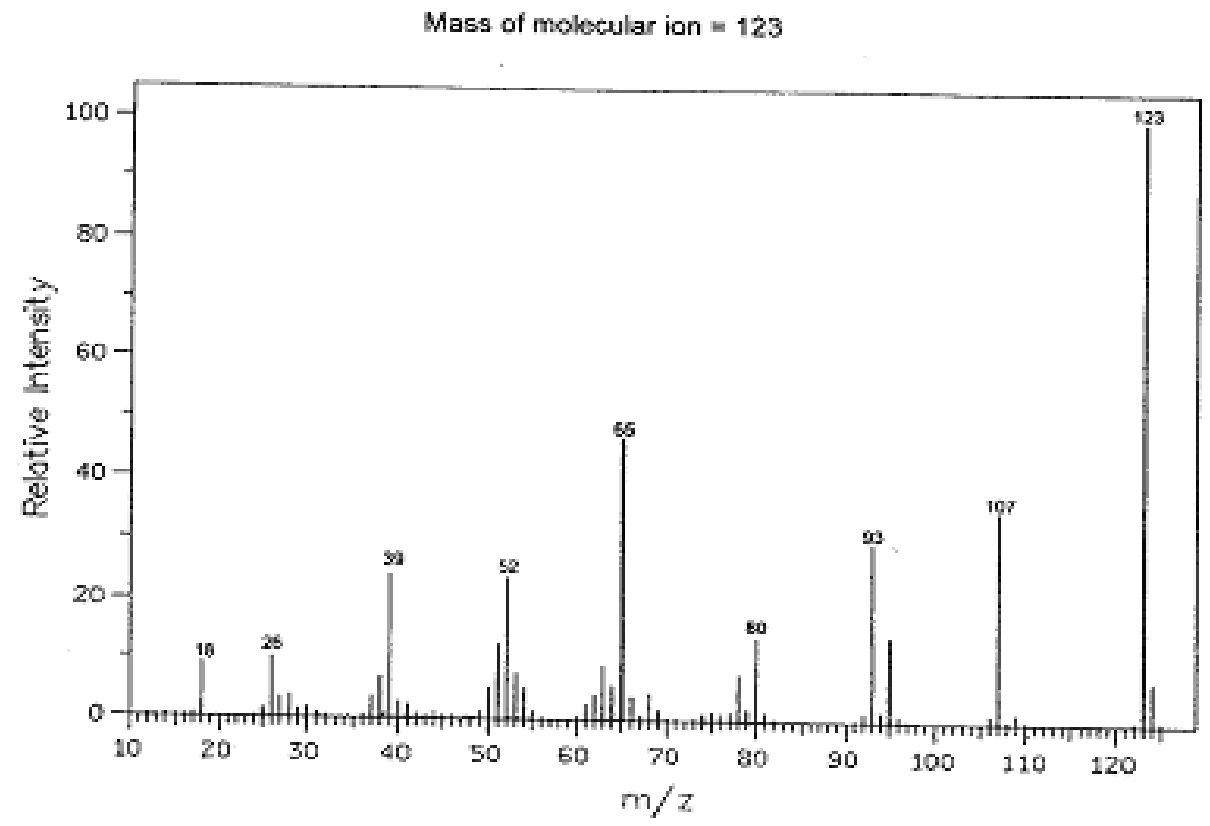

Figure 1. GC- Mass Spectrum of Quinone Oxime with its molecular ion peak at 123

\section{Reaction Orders}

The reaction orders were determined from the slopes of $\log k_{o b s} v s \log$ (concentration) plots by varying the concentration of the reductant and alkali in turn while keeping other conditions constant. The DPA concentration was varied in the range of $3.0 \times 10^{-6}$ to $5.0 \times 10^{-}$ ${ }^{5} \mathrm{~mol} \mathrm{dm}{ }^{-3}$ and the linearity of the plots of log absorbance $v$ s time up to $85 \%$ completion of the reaction, indicates a reaction order of unity in [DPA]. This is also confirmed by varying of [DPA], which did not result in any change in the pseudo first order rate constants, $k_{o b s}$ (Table 1). The paracetamol concentration was varied in the range $8.0 \times 10^{-5}$ to $8.0 \times 10^{-4} \mathrm{~mol}$ $\mathrm{dm}^{-3}$ at $25^{\circ} \mathrm{C}$ while keeping other reactant concentrations and conditions constant. The $k_{\text {obs }}$ values increased with the increase in concentration of paracetamol indicating an apparent less than unit order dependence on [PAM] (Table.1). This is also confirmed in the plots of $k_{o b s} v s[\mathrm{PAM}]^{0.58}$ in which it is linear rather than the direct plot of $k_{o b s} v s$ [PAM] (Figure 2). The effect of alkali on the reaction has been studied in the range of $6.0 \times 10^{-4}$ to $1.0 \times 10^{-2}$ mol dm$~^{-3}$ at constant concentrations of paracetamol, DPA and a constant ionic strength of $0.01 \mathrm{~mol} \mathrm{dm}^{-3}$. The rate constants increased with increasing [alkali] and the order was found to be less than unity (Table 1). 
Table 1. Effect of $[\mathrm{DPA}],[\mathrm{PAM}],\left[\mathrm{IO}_{4}^{-}\right]$and $\left[\mathrm{OH}^{-}\right]$on diperiodatoargentate (III) oxidation of paracetamol in alkaline medium at $25^{\circ} \mathrm{C}, \mathrm{I}=0.01 \mathrm{~mol} \mathrm{dm}^{-3}$.

\begin{tabular}{cccccc}
\hline $\begin{array}{c}{[\mathrm{DPA}] \times 10^{5}} \\
\left(\mathrm{~mol} \mathrm{dm}^{-3}\right)\end{array}$ & $\begin{array}{c}{[\mathrm{PAM}] \times 10^{4}} \\
\left(\mathrm{~mol} \mathrm{dm}^{-3}\right)\end{array}$ & $\begin{array}{c}{\left[\mathrm{IO}_{4}^{-}\right] \times 10^{3}} \\
\left(\mathrm{~mol} \mathrm{dm}^{-3}\right)\end{array}$ & $\begin{array}{c}\left.\mathrm{OH}^{-}\right] \times 10^{3} \\
\left(\mathrm{~mol} \mathrm{dm}^{-3}\right)\end{array}$ & $\begin{array}{c}k_{\text {obs }} \times 0^{3}\left(\mathrm{~s}^{-1}\right) \\
\text { Found Calculated }\end{array}$ \\
\hline 0.1 & 5.0 & 0.2 & 4.0 & 3.00 & 2.99 \\
0.3 & 5.0 & 0.2 & 4.0 & 3.04 & 2.99 \\
0.5 & 5.0 & 0.2 & 4.0 & 3.00 & 2.99 \\
0.8 & 5.0 & 0.2 & 4.0 & 3.05 & 2.99 \\
1.0 & 5.0 & 0.2 & 4.0 & 3.00 & 2.99 \\
& & & & & \\
0.5 & 0.8 & 0.2 & 4.0 & 1.00 & 0.95 \\
0.5 & 1.0 & 0.2 & 4.0 & 1.14 & 1.14 \\
0.5 & 3.0 & 0.2 & 4.0 & 2.31 & 2.35 \\
0.5 & 5.0 & 0.2 & 4.0 & 3.00 & 2.99 \\
0.5 & 8.0 & 0.2 & 4.0 & 3.80 & 3.53 \\
& & & & & \\
0.5 & 5.0 & 0.1 & 4.0 & 3.65 & 3.34 \\
0.5 & 5.0 & 0.2 & 4.0 & 3.00 & 2.99 \\
0.5 & 5.0 & 0.5 & 4.0 & 2.40 & 2.28 \\
0.5 & 5.0 & 0.8 & 4.0 & 2.00 & 1.84 \\
0.5 & 5.0 & 1.0 & 4.0 & 1.89 & 1.63 \\
& & & & & \\
0.5 & 5.0 & 0.2 & 0.6 & 1.38 & 1.40 \\
0.5 & 5.0 & 0.2 & 0.8 & 1.63 & 1.63 \\
0.5 & 5.0 & 0.2 & 1.0 & 1.90 & 1.96 \\
0.5 & 5.0 & 0.2 & 2.0 & 2.44 & 2.46 \\
0.5 & 5.0 & 0.2 & 4.0 & 3.00 & 2.99 \\
0.5 & 5.0 & 0.2 & 6.0 & 3.10 & 3.20 \\
0.5 & 5.0 & 0.2 & 8.0 & 3.11 & - \\
0.5 & 5.0 & 0.2 & 10.0 & 3.12 & - \\
\hline
\end{tabular}

Effect of [periodate]

Periodate was varied from $1.0 \times 10^{-4}$ to $1.0 \times 10^{-3}$ at constant [DPA], [PAM] and ionic strength. It was observed that the rate constants decreased by increasing $\left[\mathrm{IO}_{4}^{-}\right]$(Table 1).

Effect of product, [Ag (I)]

Initially added products, Ag (I), sodium acetate and quinone oxime did not have any significant effect on the rate of reaction.

\section{Effect of Ionic strength (I) and Dielectric constant of the Medium (D)}

The addition of $\mathrm{KNO}_{3}$, to increase the ionic strength of the reaction, increased the rate of reaction at constant [DPA], [PAM], [OH$]$ and $\left[\mathrm{IO}_{4}^{-}\right]$; the plot of $\log k_{o b s} v s \sqrt{\mathrm{I}}$ was found to be linear with positive slope. (Figure 3).

Dielectric constant of the medium, ' $\mathrm{D}$ ' was varied by varying the t-butyl alcohol and water percentage. The $D$ values were calculated from the equation $D=D_{w} V_{w}+D_{B} V_{B}$, where $D_{w}$ and $D_{B}$ are dielectric constants of pure water and t-butyl alcohol respectively and $\mathrm{V}_{\mathrm{w}}$ and $\mathrm{V}_{\mathrm{B}}$ are the volume fractions of components water and t-butyl alcohol respectively in 
the total mixture. The decrease in dielectric constant of the reaction medium, increase the rate and the plot of $\log k_{o b s} v s$ 1/D was linear with negative slope (Figure 3).

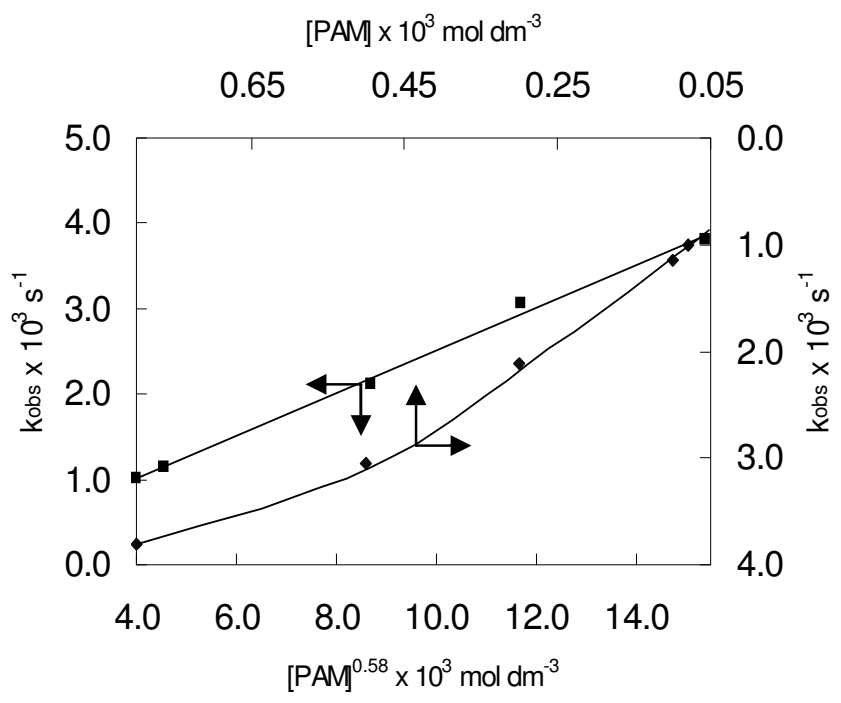

Figure 2. Plot of $k_{o b s} v s[\mathrm{PAM}]^{0.58}$ and $k_{o b s} v s$ [PAM]

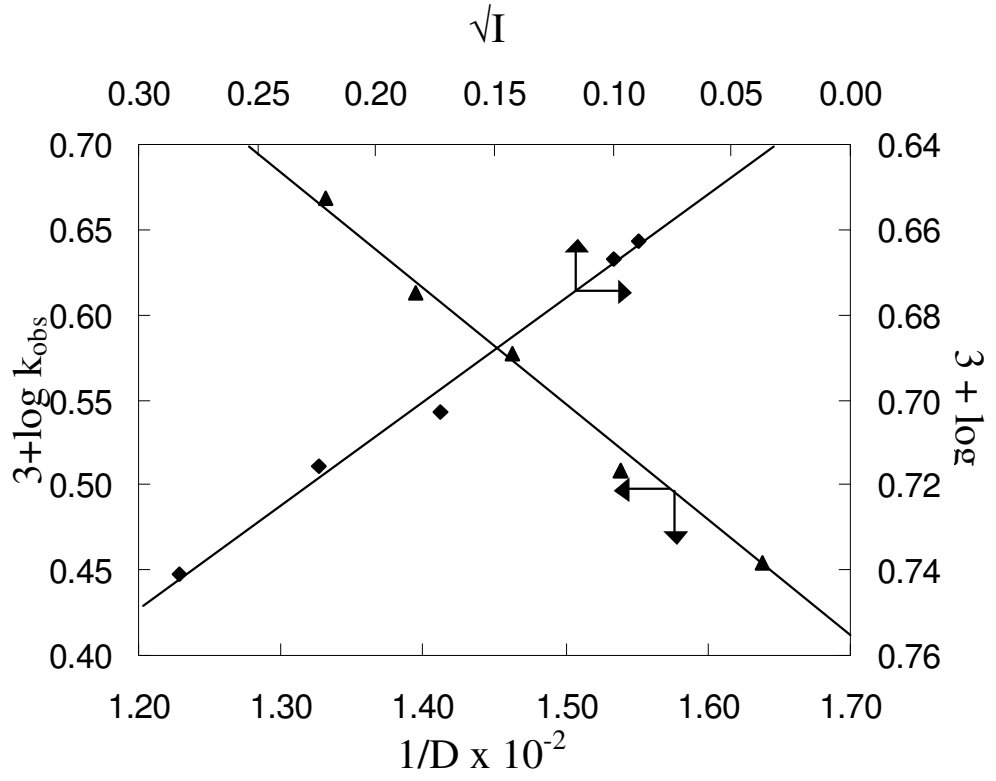


Figure 3. Effect of ionic strength and dielectric constant of the medium on oxidation of paracetamol by Diperiodatoargentate (III) at $25^{\circ} \mathrm{C}$.

Oxidation of Paracetamol Drug by a New Oxidant

\section{Effect of Temperature (T)}

The influence of temperature on the $k_{o b s}$ values were studied at $25,30,35$ and $40{ }^{\circ} \mathrm{C}$. The rate constants, $k$, of the slow step of Scheme 1 were obtained from the intercepts of $1 / k_{o b s} v s$ $1 /[\mathrm{PAM}]$ plots at four different temperatures. The values are given in (Table 2). The activation parameters for the rate determining step were obtained by the least square method of plot of $\log \mathrm{k} v s$ 1/T and are presented in (Table 2).

\section{Test for Free radicals}

The intervention of free radicals was examined as follows, the reaction mixture, to which a known quantity of acrylonitrile scavenger had been added initially, was kept in an inert atmosphere for $1 \mathrm{~h}$ Upon diluting the reaction mixture with methanol, no precipitate resulted, suggesting there is no participation of free radicals in the reaction.

In the later period of $20^{\text {th }}$ century the kinetics of oxidation of various organic and inorganic substrates have been studied by Ag (III) species which may be due to its strong versatile nature of two electrons oxidant. Among the various species of $\mathrm{Ag}$ (III), $\mathrm{Ag}(\mathrm{OH})_{4}$, diperiodatoargentate (III) and ethylenebis (biguanide), (EBS), silver (III) are of maximum attention to the researcher due to their relative stability. ${ }^{12}$ The stability of $\mathrm{Ag}(\mathrm{OH})_{4}{ }^{-}$is very sensitive towards traces of dissolved oxygen and other impurities in the reaction medium whereupon it had not drawn much attention. However, the other two forms of $\mathrm{Ag}$ (III) ${ }^{5,6,7,13}$ are considerably stable; the DPA is used in highly alkaline medium and EBS is used in highly acidic medium.

The literature survey ${ }^{9}$ reveals that the water soluble diperiodatoargentate (III) (DPA) has a formula $\left[\mathrm{Ag}\left(\mathrm{IO}_{6}\right)_{2}\right]^{7-}$ with $\mathrm{dsp}^{2}$ configuration of square planar structure, similar to diperiodatocopper (III) complex with two bidentate ligands, periodate to form a planar molecule. When the same molecule is used in alkaline medium, it is unlike to be existed as $\left[\mathrm{Ag}\left(\mathrm{IO}_{6}\right)_{2}\right]^{7-}$ as periodate is known to be in various protonated forms ${ }^{14,15}$ depending on $\mathrm{pH}$ of the solution as $\mathrm{H}_{5} \mathrm{IO}_{6}$ and $\mathrm{H}_{4} \mathrm{IO}_{6}{ }^{-}$in $\mathrm{pH} \leq 7 ; \mathrm{H}_{3} \mathrm{IO}_{6}{ }^{2-}$ and $\mathrm{H}_{2} \mathrm{IO}_{6}{ }^{3-}$ in $\mathrm{pH}>7$ and dimeric form, $\mathrm{H}_{2} \mathrm{I}_{2} \mathrm{O}_{10}{ }^{4-}$ in alkaline medium with highly concentrated solution. However, $\mathrm{H}_{5} \mathrm{IO}_{6}$, $\mathrm{H}_{4} \mathrm{IO}_{6}{ }^{-}$and $\mathrm{H}_{2} \mathrm{I}_{2} \mathrm{O}_{10}{ }^{4-}$ may be neglected as the reaction medium is alkaline and low $\left[\mathrm{IO}_{4}^{-}\right]$ used in the study. Hence, the $\mathrm{IO}_{4}{ }^{-}$is existed as either $\mathrm{H}_{3} \mathrm{IO}_{6}{ }^{2-}$ and $\mathrm{H}_{2} \mathrm{IO}_{6}{ }^{3-}$ or both. Therefore, under the present condition, diperiodatoargentate (III) may be depicted as $\left[\mathrm{Ag}\left(\mathrm{H}_{3} \mathrm{IO}_{6}\right)_{2}\right]^{-}$. The similar speciation of periodate in alkali was proposed ${ }^{16}$ for diperiodatonickelate (IV). On contrary, the authors ${ }^{6}$ in their recent past studies have proposed the DPA as $\left[\mathrm{Ag}(\mathrm{HL})_{2}\right]^{\mathrm{x}-}$ in which ' $\mathrm{L}$ ' is a periodate with uncertain number of protons or ' $\mathrm{HL}$ ' is a protonated periodate of uncertain number of protons. This can be ruled out by considering the alternative form ${ }^{14}$ of $\mathrm{IO}_{4}{ }^{-}$at $\mathrm{pH}>7$ which is in the form $\mathrm{H}_{3} \mathrm{IO}_{6}{ }^{2-}$ in the $\mathrm{pH}$ range 7-12 and $\mathrm{H}_{2} \mathrm{IO}_{6}{ }^{3-}$ of $\mathrm{pH} \geq 12$. Hence, DPA could be as $\left[\mathrm{Ag}\left(\mathrm{H}_{3} \mathrm{IO}_{6}\right)_{2}\right]^{-}$or $\left[\mathrm{Ag}\left(\mathrm{H}_{2} \mathrm{IO}_{6}\right)\right]^{3-}$ depending on $\mathrm{pH}$ of the reaction medium.

Since, the reaction was enhanced by $\left[\mathrm{OH}^{-}\right]$, added periodate retarded the rate and first order dependency in [DPA] and fractional order in [PAM], the following mechanism has been proposed which also explains all other experimental observations. 


$$
\begin{aligned}
& \mathrm{Ag}(\mathrm{HL})_{2}+\mathrm{OH}^{-} \stackrel{\mathrm{K}_{1}}{\rightleftharpoons} \mathrm{Ag} \mathrm{L}(\mathrm{HL})+\mathrm{H}_{2} \mathrm{O} \\
& \mathrm{AgL}(\mathrm{HL})+2 \mathrm{H}_{2} \mathrm{O} \underset{\mathrm{K}_{3}}{\stackrel{\mathrm{K}_{2}}{\rightleftharpoons}} \mathrm{Ag} \mathrm{L}\left(\mathrm{H}_{2} \mathrm{O}\right)_{2}+\mathrm{HL} \\
& \mathrm{Ag} \mathrm{L}\left(\mathrm{H}_{2} \mathrm{O}\right)_{2}+\mathrm{S} \rightleftharpoons \text { Complex (C) } \\
& \text { Complex }(\mathrm{C}) \underset{\text { Slow }}{\stackrel{\mathrm{k}}{\longrightarrow}} \mathrm{I}+\mathrm{Ag}(\mathrm{I})+\mathrm{L} \quad(\mathrm{I} \longrightarrow \text { Intermediate }) \\
& \mathrm{I}+\mathrm{Ag} \mathrm{L}\left(\mathrm{H}_{2} \mathrm{O}\right)_{2} \stackrel{\text { fast }}{\longrightarrow} \text { Products }
\end{aligned}
$$

Scheme 1.General Mechanistic Scheme for the paracetamol Oxidation by Diperiodatoargentate (III)

$$
\left.\left[\mathrm{Ag}\left(\mathrm{H}_{2} \mathrm{IO}_{6}\right)\left(\mathrm{H}_{3} \mathrm{IO} \mathrm{O}_{6}\right)\right]^{2-}+2 \mathrm{H}_{2} \mathrm{O} \stackrel{\mathrm{K}_{2} \longrightarrow}{\rightleftharpoons}\left[\mathrm{Ag}\left(\mathrm{H}_{3} \mathrm{IO}\left(\mathrm{H}_{6}\right)_{2}\right]^{-}+\mathrm{OH}\right)\left(\mathrm{H}_{2} \mathrm{O}\right)_{2}\right]+\mathrm{H}_{3} \mathrm{IO}_{6}{ }^{2-}
$$

Scheme 1. Detailed Scheme for the oxidation of paracetamol by alkaline Diperiodatoargentate (III)

In the prior equilibrium step 1 , the $\left[\mathrm{OH}^{-}\right]$deprotonates the DPA to give a deprotonated diperiodatoargentate (III); in the second step displacement of a ligand, periodate takes place to give free periodate which is evidenced by decrease in the rate with increase in [periodate] (Table 1). It may be expected that lower Ag (III) periodate species such as MPA is more important in the reaction than the DPA. The inverse fractional order in $\left[\mathrm{H}_{3} \mathrm{IO}_{6}\right]^{2-}$ might also be due to this reason. In the pre rate determining stage, this monoperiodateargentate (III) 
(MPA), combines with a molecule of PAM to give an intermediate complex which decomposes in a slow step to give the intermediate species by two equivalent change of

$\mathrm{Ag}$ (III) in a single step as no intervention of free radical has been observed. Then one more molecule of MPA further reacts with intermediate in a fast step to give products. (Scheme 1). The direct plot of $k_{o b s} v s$ [PAM] was not linear with intercept to know the parallel reaction if any along with interaction of oxidant and reductant. However, the MichelisMenten plot proved the complex formation between oxidant and reductant, which explains less than unit order in [PAM]. Thus, in Scheme 1, the parallel reaction and involvement of two molecules of PAM in the intermediate complex are excluded. On the basis of square planar structure of DPA, the structures of MPA and complex may be proposed as below

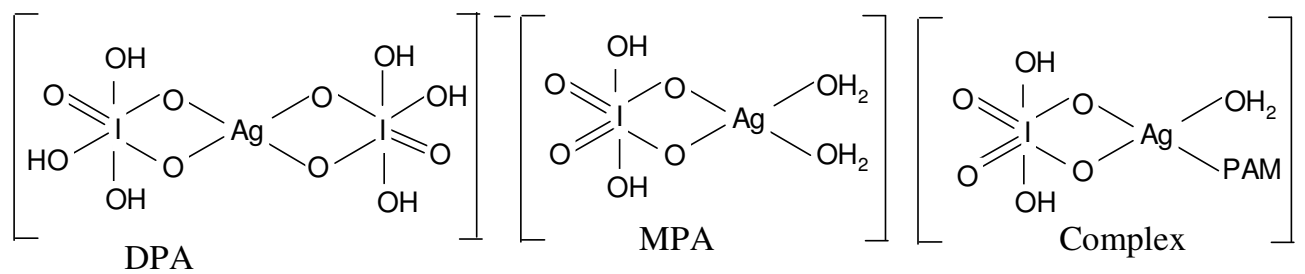

The nitrogen atom of the PAM is involved in the formation of complex, as the molecular order in PAM and the absence of the intervention of free radical redundant such a possibility. The evidence for complex formation between oxidant and substrate was obtained by nonzero intercept of the plot of $1 / k_{o b s}$ vs $1 /[$ PAM]. Spectroscopic evidence for the complex formation between oxidant and substrate was obtained from UV-Vis spectra of paracetamol $\left(0.5 \times 10^{-3}\right)$, DPA $\left.\left(5.0 \times 10^{-5}\right),\left[\mathrm{OH}^{-}\right]=0.004 / \mathrm{mol} \mathrm{dm}{ }^{-3}\right)$ and mixture of both. A hypsochromic shift of about $19 \mathrm{~nm}$ from 254 to $235 \mathrm{~nm}$ in the spectra of DPA was observed and hyperchromicity was observed at $235 \mathrm{~nm}$. The rate law for the Scheme 1 could be derived as,

$$
\begin{gathered}
\text { Rate }=-\frac{\mathrm{d}[\mathrm{DPA}]}{\mathrm{dt}}=\left[\mathrm{H}_{3} \frac{\mathrm{kK}_{1} \mathrm{~K}_{2} \mathrm{~K}_{3}[\mathrm{Ag}(\mathrm{III})]+\mathrm{PAM}_{1}\left[\mathrm{OH}^{-}\right]\left[\mathrm{H}_{3} \mathrm{IO}_{6}{ }^{2-}\right]+\mathrm{K}_{1} \mathrm{~K}_{2}\left[\mathrm{OH}^{-}\right]+\mathrm{K}_{1} \mathrm{~K}_{2} \mathrm{~K}_{3}[\mathrm{OH}]}{\mathrm{PAM}]}\right. \text { (1) } \\
\mathrm{k}_{\mathrm{obs}}=\frac{\mathrm{kK}_{1} \mathrm{~K}_{2} \mathrm{~K}_{3}[\mathrm{PAM}]\left[\mathrm{OH}^{-}\right]}{\left[\mathrm{H}_{3} \mathrm{IO}_{6}{ }^{2-}\right]+\mathrm{K}_{1}\left[\mathrm{OH}^{-}\right]\left[\mathrm{H}_{3} \mathrm{IO}_{6}{ }^{2-}\right]+\mathrm{K}_{1} \mathrm{~K}_{2}\left[\mathrm{OH}^{-}\right]+\mathrm{K}_{1} \mathrm{~K}_{2} \mathrm{~K}_{3}\left[\mathrm{OH}^{-}\right][\mathrm{PAM}]}
\end{gathered}
$$

Which explains all the observed kinetic orders of different species.

The rate law (2) can be rearranged into the following form which is suitable for verification.

$$
\frac{1}{\mathrm{k}_{\mathrm{ob}}}=\frac{\left[\mathrm{H}_{3} \mathrm{IO}_{6}{ }^{2-}\right]}{\mathrm{kK}_{1} \mathrm{~K}_{2} \mathrm{~K}_{3}\left[\mathrm{OH}^{-}\right][\mathrm{PAM}]}+\frac{\left[\mathrm{H}_{3} \mathrm{IO}_{6}{ }^{2-}\right]}{\mathrm{kK}_{2} \mathrm{~K}_{3}[\mathrm{PAM}]}+\frac{1}{\mathrm{kK}_{3}[\mathrm{PAM}]}+\frac{1}{\mathrm{k}}
$$

The plots of $1 / k_{\text {obs }}$ vs. $\left[\mathrm{H}_{3} \mathrm{IO}_{6}\right]^{2-}, 1 /\left[\mathrm{OH}^{-}\right]$and $1 /[\mathrm{PAM}]$ were linear (Fig. IV); from the intercepts and slopes of such plots, the reaction constants $\mathrm{K}_{1}, \mathrm{~K}_{2}, \mathrm{~K}_{3}$ and $\mathrm{k}$ were calculated as $(7.36 \pm 0.30) \mathrm{dm}^{3} \mathrm{~mol}^{-1},(6.6 \pm 0.1) \times 10^{-3} \mathrm{~mol} \mathrm{dm}^{-3},(5.81 \pm 0.14) \times 10^{3} \mathrm{dm}^{3} \mathrm{~mol}^{-1},(5.0 \pm$ $0.2) \times 10^{-3} \mathrm{~s}^{-1}$ respectively. These constants were used to calculate the rate constants and compared with the experimental $k_{o b s}$ values and found to be in reasonable agreement with each other, which fortifies the Scheme 1.

At higher concentration of $\mathrm{OH}^{-},\left[\mathrm{OH}^{-}\right]>>\left[\mathrm{H}_{3} \mathrm{IO}_{6}{ }^{2-}\right]$, the rate equation (2) takes the form of equation (3) by neglecting $\left[\mathrm{H}_{3} \mathrm{IO}_{6}{ }^{2-}\right]$.

$$
\mathrm{k}_{\mathrm{obs}}=\frac{\mathrm{kK}_{1} \mathrm{~K}_{7} \mathrm{~K}_{3}[\mathrm{PAM}]}{\left.\mathrm{K}_{1}\left[\mathrm{H}_{3} \mathrm{IO}_{6}{ }^{2-}\right]+\mathrm{K}_{1} \mathrm{~K}_{2}+\mathrm{K}_{1} \mathrm{~K}_{2} \mathrm{~K}_{3}\right][\mathrm{PAM}]}
$$


which is independent of $\left[\mathrm{OH}^{-}\right]$.This is actually observed in our experiment at higher concentration of $\mathrm{OH}^{-}$(Table 1).

Table 2. Thermodynamic activation parameters for the oxidation of Paracetamol by DPA in aqueous alkaline medium with respect to the slow step of Scheme 1

(A) Effect of temperature

\begin{tabular}{cc}
\hline Temperature $(\mathrm{K})$ & $k \times 10^{3}\left(\mathrm{~s}^{-1}\right)$ \\
\hline 298 & 5.04 \\
303 & 6.81 \\
308 & 8.91 \\
313 & 11.8 \\
\hline
\end{tabular}

(B) Activation Parameters (Scheme 1)

\begin{tabular}{cc} 
Parameters & Values \\
\hline $\mathrm{Ea}\left(\mathrm{kJ} \mathrm{mol}^{-1}\right)$ & $43.8 \pm 0.5$ \\
$\Delta \mathrm{H}^{\#}\left(\mathrm{~kJ} \mathrm{~mol}^{-1}\right)$ & $41 \pm 2$ \\
$\Delta \mathrm{S}^{\#}\left(\mathrm{JK}^{-1} \mathrm{~mol}^{-1}\right)$ & $-150 \pm 10$ \\
$\Delta \mathrm{G}^{\#}\left(\mathrm{~kJ} \mathrm{~mol}^{-1}\right)$ & $86 \pm 5$ \\
$\log \mathrm{A}$ & $5.4 \pm 0.2$
\end{tabular}

(C) Effect of temperature on the values of $\mathrm{K}_{1}, \mathrm{~K}_{2}$ and $\mathrm{K}_{3}$ for the oxidation of paracetamol by diperiodatoargentate(III) in alkaline medium.

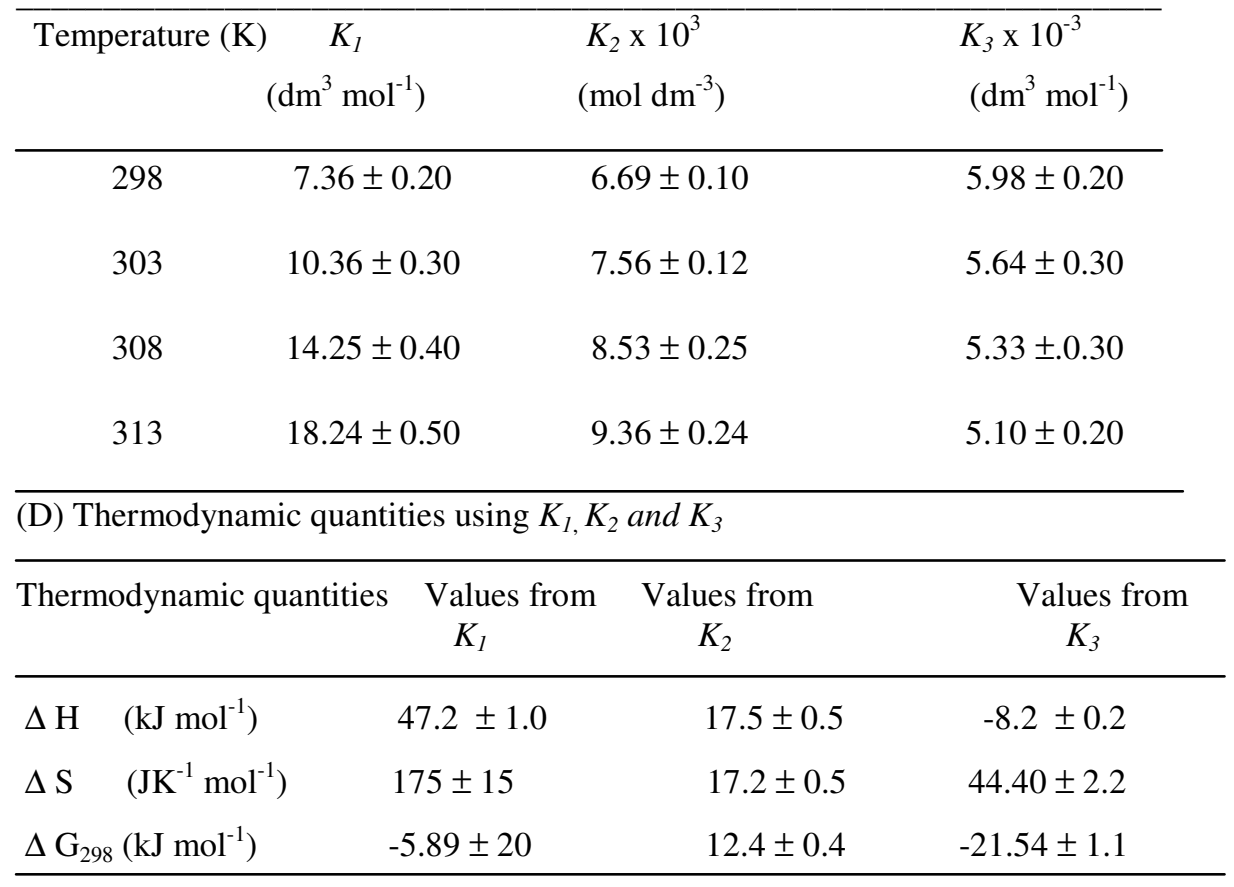


The effect of the solvent of the reaction kinetics has been described in detail in the literature $^{17,18}$. For the limiting case of zero angle approach between two dipoles or an ion-

dipole system, Leffler ${ }^{19}$ has shown that a plot of $\log k_{o b s} v s$ 1/D is linear with a negative slope for a reaction between a negative ion and dipole or two dipoles, and with a positive slope for a positive ion-dipole interaction. In the present study $\log k_{o b s} v s 1 / \mathrm{D}$ is linear with negative slope (Fig.3), which is in agreement with proposed Scheme 1

The thermodynamic quantities for the different equilibrium steps, in Scheme 1 can be evaluated as follows. The paracetamol and hydroxide ion concentrations (Table 1) were varied at different temperatures. The plots of $1 / k_{\text {obs }}$ vs $1 /[\mathrm{PAM}](\mathrm{r} \geq 0.9944, \mathrm{~S} \leq 0.2512)$ and $1 / k_{\text {obs }}$ vs $1 /\left[\mathrm{OH}^{-}\right](\mathrm{r} \geq 0.9953, \mathrm{~S} \leq 0.4501)$ should be linear as shown in (Fig. 4). From the slopes and intercepts, the values of $\mathrm{K}_{1}$ are calculated at different temperatures. A van't Hoff's plot was made for the variation of $\mathrm{K}_{1}$ with temperature [i.e., $\log \mathrm{K}_{1}$ vs $1 / \mathrm{T}$ ( $\mathrm{r} \geq$ $0.9964, \mathrm{~S} \leq 0.5801)$ ] and the values of the enthalpy of reaction $\Delta \mathrm{H}$, entropy of reaction $\Delta \mathrm{S}$ and free energy of activation $\Delta \mathrm{G}$, were calculated. These values are also given in (Table 2). A comparison of the latter values with those obtained for the slow step of the reaction shows that these values mainly refer to the rate limiting step, supporting the fact that the reaction before the rate determining step is fairly slow and involves a high activation energy. ${ }^{20}$ In the same manner, $\mathrm{K}_{2}$ and $\mathrm{K}_{3}$ values were calculated at different temperatures and the corresponding values of thermodynamic quantities are given in (Table 2).

The negative value of $\Delta S^{\#}$ suggests that the intermediate complex is more ordered than the reactants. ${ }^{21}$ The observed modest enthalpy of activation and a higher rate constant for the slow step indicates that the oxidation presumably occurs via an inner-sphere mechanism. This conclusion is supported by earlier observations. ${ }^{22}$

\section{Conclusion}

Among various species of DPA in alkaline medium, $\left[\mathrm{Ag}\left(\mathrm{H}_{2} \mathrm{IO}_{6}\right)\left(\mathrm{H}_{3} \mathrm{IO}_{6}\right)\right]^{2-}$ is considered as active species for the title reaction. It becomes apparent that in carrying out this reaction, the role of the reaction medium is crucial. The overall mechanistic sequence described here is consistent with product studies, mechanistic studies and kinetic studies.

\section{References}

1. Graham G G and Scott K F Mechanism of action of paracetamol. Am. J. Ther. 2005, 12, 46.

2. Kulkarni R M, Bilehal D C and Nandibewoor S T J. Chem. Res. 2002, (M) 401, (S) 147.

3. Puttaswamy and Anuradha T M Proc. Ind. Acad. Sci. Chem. Sci. 1999, 14, 601.

4. Sethuram B, Some Aspects of Electron Transfer Reactions Involving Organic Molecules; Allied Publishers (P) Ltd., New Delhi, 2003, p.151.

5 Jaiswal P K and Yadava K L Talanta. 1970, 17, 236; Jaiswal P K Analyst. 1972, 1, 503.

6. Jayaprakash Rao P, Sethuram B and Navaneeth Rao T React. Kinet. Catal. Lett. 1985, 29, 289; Venkata Krishna K and Jayaprakash Rao P. Ind. J. Chem. 1998, 37A, 1106.

7. Anil Kumar, Paresh Kumar and Ramamurthy P Polyhedron 1999, 18, 773 Anil Kumar and Paresh Kumar J. Phy. Org. Chem. 1999, 12, 79.

8. Tuwar S M, Nandibewoor S T and Raju J R J. Indian Chem. Soc. 1992, 69, 651.

9. Cohen G L and Atkinson G Inorg. Chem. 1964, 3, 1741. 
10. Jeffery G H, Bassett J, Mendham J and Denney R C Vogel's Textbook of Quantitative Chemical Analysis $5^{\text {th }}$ ed.; Longmans Singapore Publishers Pte Ltd. Singapore 1996, p.391.

11. Fiegl F. Spot Tests in Organic Analysis ,Elsevier, New York, 1975,p.455.

12. Krishenbaum L J and Mrozowski L Inorg. Chem. 1978, 17, 3718.

13. Cotton F A and Wilkinson G Advanced Inorganic Chemistry. John Wiley and sons, New York 1980,p.974,; Banerjee R, Das K, Das A and Dasgupta S Inorg. Chem. 1989, 28, 585; Banerjee R, Das R and Mukhopadhyay S J. Chem. Soc. Dalton Trans. 1992,1317.

14. Crouthamel C E, Meek H V, Martin D S and Banus C V J. Am. Chem. Soc. 1949, 71, 3031; Crouthamel C E, Hayes A M and Martin D S J. Am. Chem. Soc. 1951, 73, 82.

15 Hiremath S C, Tuwar S M, Nandibewoor S T and Raju J R Ind. J. Chem. 1999, 8A, 61.

16. Bhattacharya S, Saha B, Datta A and Banerjee P Coord. Chem. Rev. 1988, 47, 170; Haines, R.I.; McAuley, A. Coord. Chem. Rev. 1981, 39, 77.

17. Moelwyn-Hughes E A. Physical Chemistry. (2 ${ }^{\text {nd }}$ ed., Pergamon Press, New York, 1961).

18. Amis E S Solvent Effects on Reaction Rates and Mechanisms. Academic Press, New York, 1966.

19. Leffler J E J. Org. Chem. 1955, 20, 1202.

20. Rangappa K S, Raghavendra M P, Mahadevappa D S and Channegouda D J. Org. Chem. 1998, 63, 531.

21. Weissberger A and Lewis E S (Ed.), Investigation of Rates and Mechanism of Reactions in Techniques of Chemistry. Wiley, New York, 1974, 4, p.421.

22. Martinez M, Pitarque M A and Eldik R V J. Chem. Soc. Dalton Trans. 1996, 2665. 


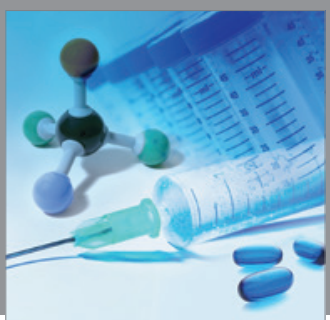

International Journal of

Medicinal Chemistry

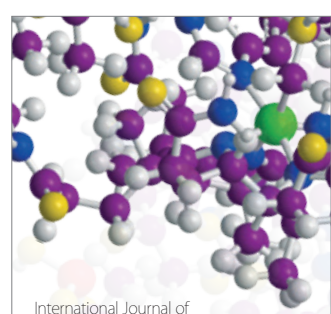

Carbohydrate Chemistry

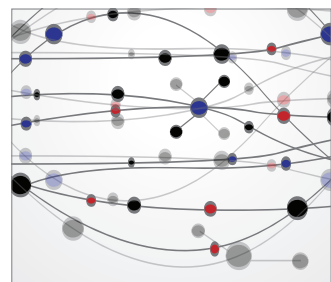

The Scientific World Journal
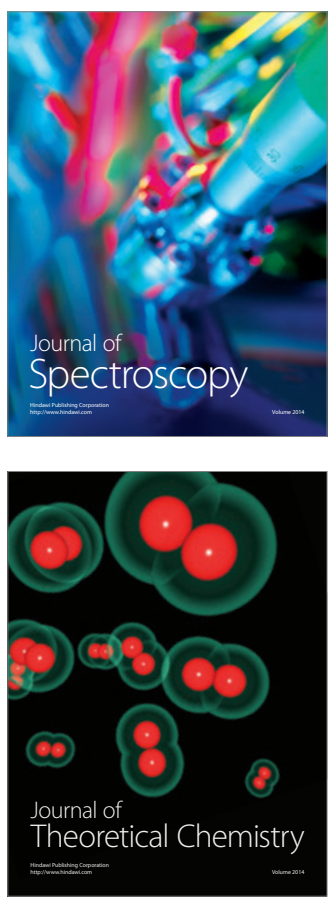
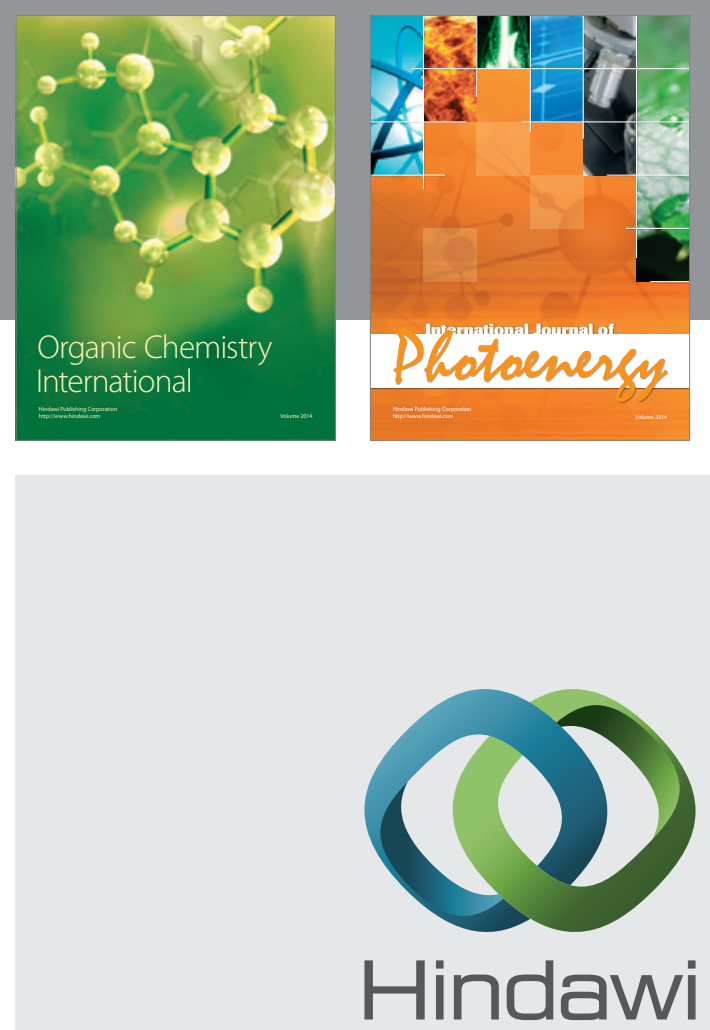

Submit your manuscripts at

http://www.hindawi.com
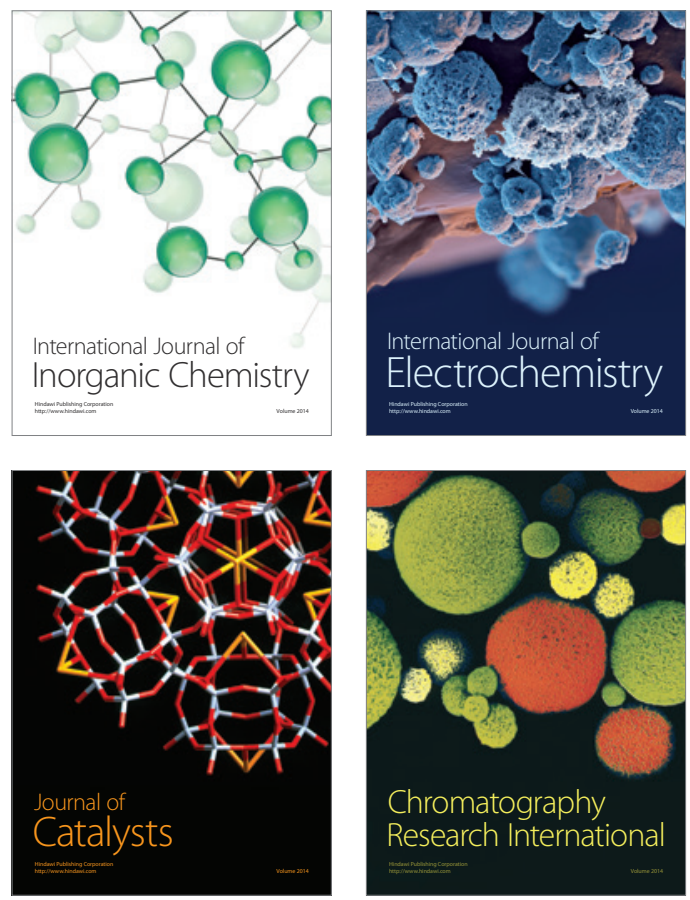
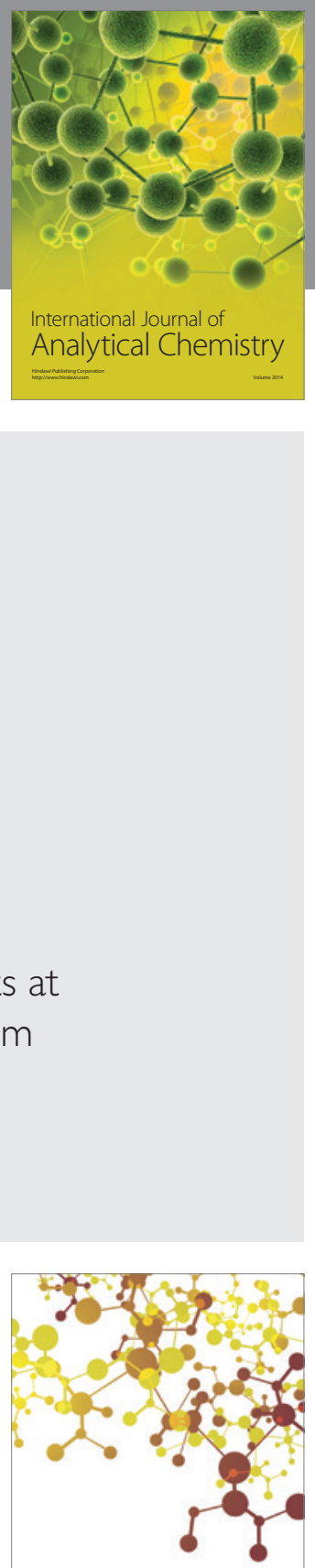

Journal of

Applied Chemistry
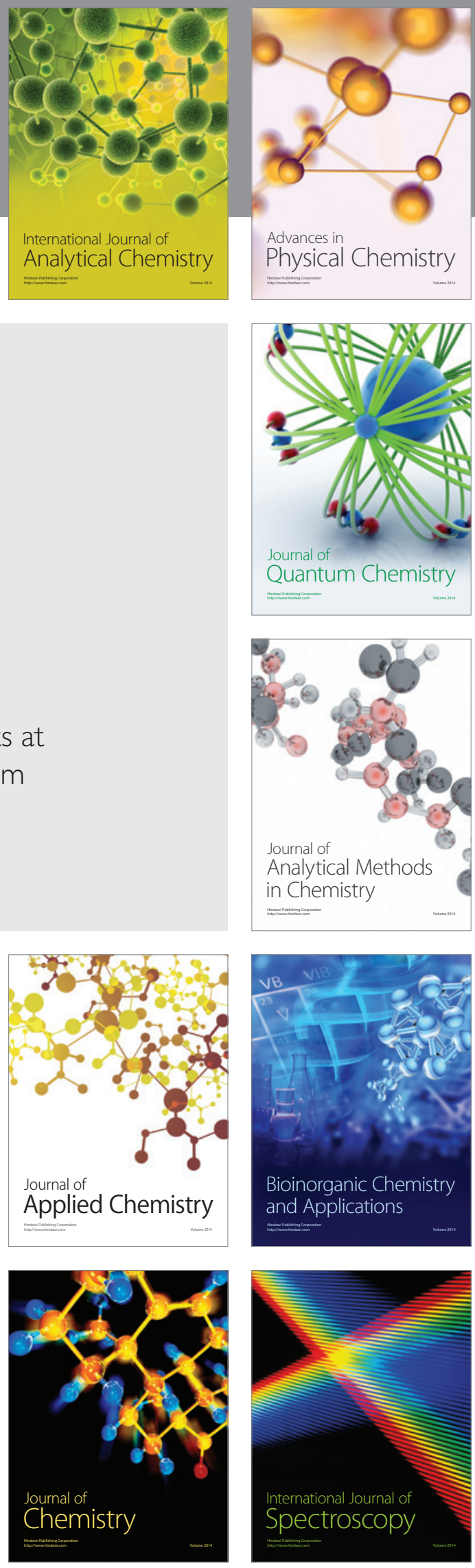